\title{
ALTERNATIVE METHODS OF INDUSTRY FINANCING FOUNDED ON RECENT INCOME TAX INNOVATIONS
}

\author{
J. C. CRAWFORD*
}

Current economic conditions are causing the oil and gas industry to examine novel techniques of project financing. The author discusses two such techniques made possible by recent changes in the tax laws. The first, based on 8s. 66.1, 66.2 and 66.3 of the Income Tax Act, permits a shareholder, in certain circumstances, to write off expenditures on Canadian Resource properties against his ordinary income. The second relates to the construction and operation of gas plants by a third party in return for a long term commitment by gas owners to use or pay for the facilities.

\section{INTRODUCTION}

Because of the depressed state of the stock market, rapid inflation, and massive capital requirements, the oil and gas industry has been forced to borrow extensively on the medium term market. Debt/equity ratios have been forced up to what have been traditionally accepted as the limit of a company's borrowing power. The prospect of borrowing money with a seven year term to be invested in a gas plant or a gas field with a twenty year life must give many financial vice-presidents cause for concern.

Project financing, therefore, is likely to become a significant aspect of oil and gas business. The two forms of business endeavours discussed in this paper could be included within a liberal definition of "Project Financing".

The financing of a company's exploration and drilling activities through the medium of "Exploration and Development Flowthrough Shares" and the financing of gas plants will be discussed on a conceptual basis. Both concepts are in the embryo state. The two types of financing are quite different in legal form, but they are really "half-brothers" because they have a common parent in the Minister of Finance in Ottawa. It remains to be seen whether they will be acknowledged as his bastard children, and be fully accepted in the cloistered society known as "Revenue Canada".

\section{EXPLORATION AND DEVELOPMENT FLOWTHROUGH SHARES}

Sections 66.1(6)(a)(v) and 66.2(5)(a)(v) of the Income Tax Act of Canada provide that "Canadian Exploration Expenses" and "Canadian Development Expenses" include expenses incurred by a taxpayer after May 6,1974, pursuant to an agreement with a company whereby the taxpayer incurs the expenses solely as consideration for treasury shares of the capital stock of the company. The company agrees to undertake an exploration and development drilling program for the production of oil and gas upon lands in Canada owned by the company, in which the company has a beneficial interest, or in which it can earn a beneficial interest by drilling. These expenditures thereby become a Canadian Exploration Expense (CEE) or a Canadian Development Expense (CDE) in the accounts of the company issuing the shares. However, pursuant to the sections of the Income Tax Act outlined above, these expenditures may be allocated to, and claimed for tax purposes by, the shareholders 
who subscribe for the shares. In effect, the subscription monies are "traced" through the company's treasury into its exploration and development budget, so that they can be credited back to the shareholders. The shareholders, therefore, notionally spend money on drilling or other exploration or development activities, just as a limited partner in a drilling and exploration limited partnership participates in such activities. However, it is only the expense which flows through to the shareholder, and not the income, as in the case of limited partners. The shareholder may only look to normal dividend income out of the general corporate funds of the company available for the payment of dividends. The shareholder must then adjust his cost base of the shares, reducing the amount of his subscription price by an amount equal to the write-off claimed against other income. Section 66.3 of the Income Tax Act provides that such shares are inventory and not capital property, as would otherwise be the case.

Since May 6, 1974, CEE expenses may be written off at an annual rate of up to $100 \%$ and CDE expenses may be claimed to reduce all income for tax purposes at a rate of $30 \%$ per annum, on a diminishing balance basis.

While the shares may be freely transferable, the exploration and development write-offs are not. Therefore, it is expected that these shares will be issued subject to an escrow arrangement whereby they will not be released to the shareholder owner until the subscription monies have been expended on the exploration and development program contemplated in the subscription agreement.

The only known public offering utilizing these concepts is the Rangeco Oil \& Gas Ltd. offering for $\$ 20,000,000$. This offering, a project of Ranger Oil (Canada) Ltd., had its preliminary prospectus filed on March 11, 1977. At this writing it is understood to be awaiting the clearance of the final prospectus. 'This issue consisted of 4,000 units, made up of 100 common shares in Rangeco for $\$ 350.00$, and a natural resource receipt for $\$ 4,650.00$. There is also a dealer's commission of $\$ 225.00$ payable out of each $\$ 5,000.00$ unit. The natural resource receipt entitles the subscribers to an undivided pro-rata interest in a royalty interest in certain undetermined lands to be acquired; it also entitles them to an undetermined number of class " $A$ " shares of Rangeco, which would generally conform to the above mentioned definition of exploration and development flowthrough shares. The proceeds from the sale of the common shares would not be utilized to incur deductible exploration and development expenditures. Only the proceeds represented by the resource receipts (less the dealer's commission) which would be so utilized. The subscribers would be entitled to deduct these expenses for income tax purposes against income from all other sources. The prospectus states that it is intended that approximately $50 \%$ of the proceeds represented by the resource receipts would be used to incur CEE (which would permit subscribers to deduct $100 \%$ of such expenses from their income for tax purposes); and approximately $50 \%$ of proceeds represented by the resource receipts would be used to incur CDE (which would permit subscribers to deduct $30 \%$ of such expenditures annually, on a declining balance basis).

The issue is said to provide subscribers with an opportunity to make a Canadian petroleum and natural gas investment under the supervision of an experienced operator, while at the same time enabling them to avail themselves of the income tax incentives designed to encourage petroleum and natural gas exploration and development in Canada. 
The resource receipts are said to indicate the subscribers' right to class "A" shares of Rangeco Oil \& Gas Ltd. and to royalty interests. The resource receipts are non-transferable and would cease to have any function after the issuance of such securities in accordance with the terms of the offering. Class " $A$ " shares are to be issued at the rate of one share for every $\$ 10.00$ of Class " $A$ " expenditures. Except for the income tax deductions, the issuing company will be the beneficiary of these expenditures.

It was a term of the issue that Class " $A$ " shares would be issued to an agent on behalf of the subscribers mentioned above. The shareholders can only look to the declararion of payment of the normal dividends as a return on the investment in these shares. It is a condition attached to these particular shares that after payment of $\$ 10.00$ in aggregate dividends, the shares may be redeemed for $\$ 10.00$. Of course, there may be a further return on the resource receipts from the royalty interests which they acquired at the same time. No dividends may be paid on the common shares until the class " $A$ " shareholders have received $\$ 10.00$ per share in aggregate dividends.

If 4,000 units of this issue are sold, 400,003 of the authorized 750,000 common shares of Rangeco will be issued.

It is said that the Directors of Rangeco expect to consider the listing of both the class " $\mathrm{A}$ " shares and the common shares on an appropriate stock exchange.

The royalty interests are expected to be derived from resource property acquired by the agent from Ranger Oil (Canada) Ltd. and under farmout agreements and assignments to Rangeco. Ranger agrees to assign an undivided $75 \%$ interest in these properties to the agent for $100 \%$ of Ranger's cost, up to the limit of the funds provided by the issue. The subscribers must pay $100 \%$ of the costs of bringing the properties into production.1 Thus Ranger has a $25 \%$ carried interest. Under the assignments to Rangeco, for a period of seven years from the commencement of production, the agent on behalf of the subscribers reserves a royalty interest in each resource property, equal to $5 \%$ of Rangeco's share of gross natural gas production from such resource property. The agent undertakes to distribute royalties received to the subscribers on a pro-rata basis.

The resource interest payments, of course, are considered to be "resource profits" for income tax purposes. The receipt of such payments will entitle subscribers to resource allowances equal to $25 \%$ of such payments and to an earned depletion allowance equal to the lesser of $25 \%$ of their resource profits (after deducting the resource allowances) or their earned depletion base. Both allowances are deductible in computing income for tax purposes.

The class "A" shares of Rangeco are said to be treated as inventory in the hands of the subscriber with a "nil" cost base. Accordingly, the proceeds received by a subscriber on a liquidation of Rangeco, a redemption of the class " $A$ " shares, or a disposition of the class " $A$ " shares, will be included in the income of the subscriber. As noted above, it is a condition attached to these shares that after the payment of $\$ 10.00$ in dividends; the shares may be redeemed for their issue price of $\$ 10.00$. Thus, with respect to the subscription price of these class " $A$ " shares, a 
subscriber will receive a maximum of double his money back, on a pretax, undiscounted basis.

In the Financial Post of March 26, 1977, a representative of McLeod, Young, Weir, the underwriters of the issue, was quoted as stating that the tax consequences of the issue had been confirmed by an income tax ruling from Ottawa.

It must be noted that there is no reference in the "Red Herring" prospectus to the manner of funding the purchase of "tangible equipment" that would be required to bring any oil and gas finds into production. The purchase of this type of equipment would be subject to a capital cost allowance pursuant to Schedule B of the Income Tax Act; but these expenditures would not qualify as CEE or CDE and there would be no flowthrough. Also, there is no mention of the 8. 12(1)(0) and 8. 18(1)(m) "phantom income" addbacks. It is assumed that Rangeco will be paying the Crown royalty for any discoveries on Crown lands, as well as the freehold mineral tax on freehold production. Therefore, these amounts must be added to its income for tax purposes. The drilling and royalty credits on amounts paid to the Alberta Treasury would not flow through to the share subscribers because they only have an undivided royalty interest in all the properties; they cannot be said to have a working interest, or any interest like a working interest, in the individual properties 80 as to participate in these credits.

It would appear that any funds expended on oil and gas exploration, drilling or development would flow through and contribute to the depletion base of the subscribers. However, any of the subscription funds expended on the purchase of a Canadian Resource property would not add to the depletion base of either the company or the subscribers.

This pioneering effort in the field of oil and gas financing is of great interest to the industry.

\section{GAS PLANT FINANCING}

To obtain saleable pipeline gas or other products, companies owning natural gas reserves in Canada must often build gas plants in the field in order to subject the raw gas to a certain amount of manufacturing and processing. Depending on the constituents in the raw gas as it is recovered from the underground reservoir, such manufacturing and processing plants will yield pipeline gas, gas liquids such as condensate, propane, butane and the heavier hydrocarbon fractions, and sulphur if the reservoir contains "sour gas".

Under certain circumstances, it is advantageous to have a third party build such plants and process the gas on a "fee for service" basis. Thus, the gas owners avoid the necessity of arranging the long term debt to fund the facilities and the third party incurs the debt obligation related to the plant.

Such plants completed after May 8, 1972 are now classed as class 29, for capital cost allowance purposes (CCA). In addition, they are currently subject to the $5 \%$ investment tax credit as processing or manufacturing equipment. ${ }^{2}$ The current class 29 CCA rate is $50 \%$ straight line depreciation which results in a full write-off in two years. A gas plant owner who for a fee processes gas for others, may claim the CCA on his plant, in order to create a "loss" (that is, a CCA claim greater than the 
processing fee net income). This loss may be written off against his other ordinary income.

The ownership of such a plant may be syndicated either through a joint venture agreement or a limited partnership agreement. This permits individuals and companies who are fully taxable to claim the CCA, and thus defer income tax on other income.

The salient features of such an arrangement are as follows:

(1) The plant owner agrees to construct, operate and expand a gas plant in accordance with the gas owner's design, operating requirements (including personnel to the owner's satisfaction) and expansion plans, on behalf of all the owners of gas that can be economically serviced by the plant;

(2) The gas owners will deliver their gas, pay the processing fee (or a deficiency fee, if contracted capacity is not utilized) to the plant owner, and take delivery of pipeline gas and other products at the plant outlet valve;

(3) Multi-party gas plant ownership agreements are avoided with the resulting simplification in mortgage financing and insurance arrangements;

(4) The gas owners may expense $100 \%$ of the processing fee for tax purposes and deduct it as an "arm's length" charge in determining the value of gas at the wellhead for lessor and gross overriding royalty, mineral income tax, and Progressive Incremental Royalty purposes. This procedure may also reduce the s. $12(1)(0)$ and $\mathrm{s}$. $18(1)(m)$ addback under the Income 'I'ax Act;

(5) Under this plan, the gas owners' operating charges on a per m.c.f. basis will always be less than a financing where the gas owners borrow 100\% of the cost of the plant (project financing) and expense the interest and operating costs against the plant's deemed income; ${ }^{3}$

(6) Under the present CICA accounting rules, this procedure will provide an effective "off balance sheet" long term financing, and debt/equity ratio and bank lines of credit of the gas owners will not be affected. If the amount of the deficiency covenant is material, it may have to be noted as a long term expenditure commitment under Rule 3280.01(d), but this should not affect the debt position of the company;

(7) This plan provides a lower effective pre-tax money cost when compared with $100 \%$ debt financing. The reason for this is that the plant owner provides for 25 to $40 \%$ of the plant costs by "equity" financing on which he accepts a more modest pre-tax return than is normally expected by the gas owner. The plant owner secures the "debt" portion of the cost by giving a mortgage on the plant together with an assignment of the proceeds of the 'Ihroughput and Deficiency Agreement. Therefore, he is able to use the "covenant" of the gas owners as part of his security for the debt;

(8) In this plan, of course, the gas owners relinquish the right to claim capital cost allowance on the plant, thereby losing the ability to defer tax or to shelter other taxable income generated by the gas owners. However, even if the ownership of the plant is retained,

3. See Texaco Exploration v. R. (1975) 29 D.T.C. 5288 for an explanation of the requirement to attribute a notional profit to a gas plant that is contributing to the "production profite" of the gas plant owner. 
part of this CCA would be required to offset the deemed income from the plant;

(9) The plan necessitates a very detailed Throughput and Deficiency Agreement with a fee based on an $A$ \& $B$ component. The $A$ component would provide a charge per m.c.f. sufficient to amortize the annual operating costs (a common factor whether the gas owners or the new plant owners had owned the plant and a pre-tax expense in both cases). The $B$ component would provide for the amortization of the debt and equity portions of the investment during the term of the Throughput and Deficiency Agreement. The A component would escalate or de-escalate with the actual costs (similar to the maintenance, insurance, taxes, etc., in a triple net building lease). Thus the gas owner would be contractually assured that the gas would be properly pocessed for sale.

\section{CONCLUSION}

It is recommended that any project utilizing the above concepts not be undertaken without a formal tax ruling from the rulings division of Revenue Canada. However, with the massive capital requirements of the resource sector of the Canadian economy, it is thought that these forms of financing are not only fiscally responsible but, indeed, to the general advantage of Canada. As a result of concern about Canada's balance of payments, we will have to provide for the maximum utilization of the Canadian capital investment dollar in this sector of our ecomomy.

Many people in the Canadian oil and gas industry welcome the changes to tax laws which may encourage innovative financing proposals similar to the above two plans. Hopefully, the policy objective of encouraging Canadian investment in this sector of our economy will be attained. It will be interesting to observe whether these and other similar proposals will continue to evolve and flourish under a fiscal stimulus. 